\title{
IMPROVING STRATEGIC DECISION-MAKING IN A CLOSED-LOOP RAIL NETWORK WITH HYBRID SIMULATION-OPTIMIZATION MODELING
}

\author{
Jorge Ubirajara Pedreira Junior ${ }^{1}$, Ademar Nogueira do Nascimento ${ }^{2}$, Cristiano Hora de \\ Oliveira Fontes $^{2}$ \\ ${ }^{1}$ Federal University of Bahia, Department of Transportation Engineering and Geodesy, R. Aristides Novis, 02, \\ Salvador (BA), Brazil. \\ ${ }^{2}$ Federal University of Bahia, Industrial Engineering Graduate Program, R. Aristides Novis, 02, Salvador (BA), \\ Brazil.
}

Corresponding Author: ${ }^{1}$ email: jorge.ubirajara@ufba.br; tel: +55 71994043873

\begin{abstract}
The availability of rail infrastructure resources is a major driver of rail operations performance. To evaluate the impact of infrastructure provision, network simulation models can be used to accurately represent train traffic behavior in a wide range of scenarios. However, performing this task can result in a problem of high combinatorial nature as the number of factors and their associated levels increase. This requires more sophisticated techniques such as experimental design formulations or optimization modeling in order to yield satisfactory results. Yet the research in network simulation models for rail systems has hitherto been limited to simple whatif analysis, made up from few factors that cannot represent the whole spectrum of interventions. This is especially critical in closed-loop rail systems where trains are subject to various interferences. Local improvements can be misleading as the queues are merely transferred within the network. Considering this, we propose a hybrid simulation-optimization model to aid the strategic decision of minimizing supplementary capital costs in a heavy-haul Brazilian railroad under construction. As soon as the railroad is completed, investments in both loading and unloading rail terminals will be necessary. First, we developed a representative and flexible model capable of dealing with complex relations between variable infrastructure provision and the resulting operational performance. Then, we simulated this system to prove that the current set of proposed infrastructure resources cannot meet the transportation demands. Afterwards, we demonstrate that local improvements can be delusive as the queues are shifted from loading to unloading operations, reciprocally. Then, we solve an optimization model to define the minimal supplementary investment in order to meet the commercial goals of mining companies. This is done by choosing the best trackage configuration, equipment quantity and capacity and fleet sizing in 3 different production scenarios. The best values of the objective function were found by improving both loading and unloading equipment and increasing the number of trains.
\end{abstract}

Keywords: Network simulation modeling; Rail Infrastructure; Hybrid-Simulation Optimization 


\section{INTRODUCTION}

Increasing demand in rail transport puts hard pressure in existing rail infrastructure. Insufficient infrastructure resources can lead to rapid congestion in rail networks (Gorman, 2009) as train delays increase exponentially with growing traffic (Sogin, Barkan and Saat, 2011). The resulting poor operational performance entail low level of service for rail costumers (Pouryousef and Lautala, 2015), worsening rail transport competitiveness.

Previous models investigated the impacts of infrastructural changes in railway operations (Dessouky and Leachman, 1995; Dessouky, Lu and Leachman, 2002; Atanassov and Dick, 2015). Although important correlations were found, these models did not cover a wide range of infrastructure parameters. This fact is particularly critical in railways running on a closed-loop framework composed by unit trains (carrying the same commodity). In such systems trains are formed once in the network with a fixed number of railcars and run through the following closed circuit without being split or stored in the route: (i) loading; (ii) moving loaded to a rail port terminal; (iii) unloading; and (iv) moving empty to a loading terminal (Franzese, Fioroni and Botter, 2003; De Faria and Cruz, 2015). Closed-loop systems are modeled as opposed to the ordinary dispatching model, where trains are formed and disposed in the edges of the network with the purpose of analyzing line utilization and total delay. Cyclic trains are subject to several interferences from both interaction with other trains and disruptions in loading and unloading processes. Therefore, local and isolated solutions are ineffective since queues are only transferred within this closed circuit.

Moreover, the railway industry is very capital intensive and the provision of infrastructure is very costly (Abril et al., 2008; Gorman, 2009). Although managing the existing capacity is a more cost-effective approach, growing traffic will eventually require capital expansion. Thus, from a wide range of possible improvements one must choose a subset that meets the expected performance at minimal cost. So far, it appears that not only rail modeling is limited to a narrow and unintegrated range of infrastructural solutions but they did also not account for the cost dimension of the decision-making process.

Against this backdrop, we propose a hybrid simulation-optimization model to fill this gap in the railway modeling research. The Brazilian heavy haul West-East Integration Railroad (Ferrovia de Integração Oeste Leste - FIOL) and its branching lines in loading and unloading operations is chosen to perform this task. We prove that the current set of infrastructure parameters will not be able to meet the transportation demands from iron ore mining companies. 
By pointing out the bottlenecks of the system, we also demonstrate that local solutions do not achieve the desired goal, demanding a broader experimental approach. This work consists of 3 steps: (a) modeling freight train traffic and associated activities within this supply chain; (b) simulating this model in a discrete-event basis to obtain the annual volume of iron ore delivered in port; (c) based upon the simulation results, minimizing total investment in tracks, vehicles and equipment in the system, subject to the mining companies' commercial goals and operational constraints.

\section{LITERATURE REVIEW}

\subsection{Railway Traffic Modeling}

The rail planning literature considers three classical levels of management decision-making: strategic, tactical and operational (Assad, 1980; Crainic and Laporte, 1997; Marinov, Zunder and Islam, 2010). Strategic decision involves the highest level of management and determines capital investments over long time horizons. Tactical planning, in turn, focuses on resource allocation to meet demand origin-destination requirements in the medium term. Finally, operational planning is concerned with day-to-day activities of the railroad, such as empty car distribution, locomotive scheduling and dispatching decisions to solve train conflicts.

An important measure to be determined in this context is rail capacity. Rail capacity is referred to as the maximum number of trains that can operate on a pre-defined infrastructure, during a specific time interval and given some operational conditions (Abril et al., 2008). A rail network consists of lines of track (links) associated with stations, junctions and yards (nodes) where freight trains undergo several activities such as classification, fueling and loading/unloading operations (Assad, 1980). A malfunctioning railway node may compromise the entire service, causing upstream delays and downstream idle periods (Marinov and Viegas, 2011). Therefore, capacity analysis must be performed in a global and integrated manner, i.e. in a network-wide perspective (Crainic and Laporte, 1997).

There are three main methods to evaluate rail capacity: analytic, optimization and simulation (Petersen and Taylor, 1982). Analytical methods aim at defining a preliminary solution, often used as a reference or comparison (Abril et al., 2008). They consist of mathematical formulae or algebraic expressions that relies on several assumptions about system modeled (e.g. queuing theory). However, modeling real-world train traffic analytically is a very complex task. Dessouky and Leachman (1995) state that compound delays and ripple effects from train conflicts pose a hard challenge on developing analytical models. 
On the other hand, optimization strategies are employed to provide the feasible best (or near best) solution to routing traffic through the rail network. These models are often concerned with minimizing total delay (or costs) or maximizing the number of trains in a timetable by means of mixed integer linear programming formulations or meta-heuristic algorithms. An extensive review of these models and methods and their applicability can be found in Caimi, Kroon and Liebchen (2017). A recent trend in optimization models is the real-time rescheduling problem, applied to when the traffic is disrupted and a new schedule must be developed quickly. Corman and Quaglietta (2015) address the main challenges in their applicability and highlight the best available control scheme to implement such solutions.

Simulation methods, in turn, attempt to imitate the movement of trains through the railway network, taking a given set of parameters such as trains, lines, yards and operation policies as inputs (Assad, 1980; Abril et al., 2008; Motraghi and Marinov, 2012). Because simulation models prescind from typical unrealistic assumptions of analytical models, they can represent very accurately real-world systems. Train traffic is rather complex and dispatching rules can be more realistic represented by simulation models (Medanic and Dorfman, 2002). Moreover, train movement in rail yards are very contingent on yard layout and operational policies that vary greatly from case to case.

Crainic, Perboli and Rosano (2018) list 4 objectives of a simulation model, namely: (a) what-if analysis, when multiple scenarios are generated by changing input values to compare system alternatives; (b) forecasting, to predict the system future performance under various conditions; (c) validation, to confirm that either a proposed scenario or a modeling approach represent the real-world system; and (d) enhancement, when the simulation is combined with techniques such as optimization modeling to improve the solution.

In the rail context, simulation methods seem to be a preferred approach between practitioners. Ferreira (1997) explains that optimization models have not been widely embraced by rail organizations because of the complexity of the overall task and practical issues (Corman and Quaglietta, 2015) that prevent optimal results from being implemented. Michal et al. (2017) reinforce that view stating that optimization models require the decision makers to have a good grasp in mathematical modeling, limiting their use in real situations.

To work with comprehensive data input a simulation tool is required. Well-known specific rail network simulation software are RailSys and OpenTrack, used in Europe, and Rail Traffic Controller (RTC), the foremost software used in North America (Motraghi and Marinov, 2012). 
It is also possible to work with general purpose simulation software such as Arena and Simul8 to represent train traffic (Marinov and Viegas, 2011). They provide an intuitive platform that eases the simulation modeling task and allows for complex reality implementation. There are also cases where new simulations platforms are developed in Michal et al. (2017) and Hernando, Roanes-Lozano and García-Álvarez (2010).

Due to the abovementioned arguments, simulation network models are the focus of this paper. Crainic, Perboli and Rosano (2018) classify the technical implementation of simulation by two perspectives. Regarding the evolution over time, these models can be either static (i.e. time is not explicitly considered, but rather the system is evaluated in a steady state) or dynamic (when the system changes over time). With respect to the inclusion of uncertainty, models can be either stochastic (when random inputs are used) or deterministic (in case the inputs are not uncertain).

\subsection{Simulation Network Models}

Dessouky and Leachman (1995) investigated the implementation of an alternative high capacity corridor near a port area served by three major railroad companies. They concluded that further improvements should be considered in order to obtain a better level of service. Later, Dessouky, Lu and Leachman (2002) proposed doubling and tripling existing tracks and the addition of a passenger train flyover to the same system. Atanassov and Dick (2015) addressed the problem of passing sidings with limited size in face of increasing train lengths. They carried out a factorial experimental design considering the number of trains, the percentage of long trains, the percent of long sidings and the directional distribution of long trains in the network. From the 196 scenarios tested (out of 224 combinations), it was demonstrated that routes with roughly $50 \%$ of long sidings eliminate any delay-based consequences of running long trains on the route. A similar challenge has also been investigated in a developed simulation tool by Hernando, Roanes-Lozano and García-Álvarez, (2010) for a Spanish railroad. Michal et al. (2017) tested 2 improvements in the unloading facility of coal cyclic trains in Australia, consisting of extending the existing coal arrivals roads to $850 \mathrm{~m}$ and doubling the existing unloading capacity. In a similar vein, Fioroni et al. (2013) evaluated the total coal transported in a Colombian railroad by upgrading a stacker-reclaimer system at port and augmenting the number of railcars in a typical coal freight train.

Although abovementioned studies contemplated improvements in infrastructure resources, most of simulation network models is focused on analyzing the network performance by 
changing the number of vehicles and/or operational policies. De Faria and Cruz (2015) modeled a major Brazilian railroad running with iron ore cyclic trains. The authors tested 3 scenarios with different number of railcars and suggest the expansion of existing tracks. Woroniuk and Marinov (2013) simulated a Spanish railway network with low line utilization in order to investigate the impact of the inclusion of a freight service.

Heterogeneity of train traffic pose a great challenge in railway networks, since passenger trains usually have higher speeds and higher priority over freight trains. Sogin, Barkan and Saat (2011) simulated 113 scenarios considering the inclusion of freight and passenger trains with different speeds, demonstrating that priority and speed differential increases the mean and variance of freight trains delays. Dingler, Lai and Barkan (2014) added other heterogeneity factors in their analysis such as acceleration/breaking rates proving its significance in average delay increase.

With respect to operational policy, Marinov and Viegas (2011) compared the performance of two productions patterns, namely improvised operations and structured-fixed schedules in a rail freight network in Portugal. In the first case, freight trains leave loading facilities only when they have enough tonnage to fill them to the capacity limits of the rail lines. This is a very common operation pattern in worldwide freight rail networks outside Center and Western Europe (Marinov and Viegas, 2011; Marinov et al., 2013). Structured-fixed schedules, in turn, are based on the philosophy that freight trains have to be as reliable as passenger, even if they run as reduced formations. In their work, Marinov and Viegas (2011) proved that rail lines and yards presented lower percent of time awaiting work, higher utilization and less saturation. Similar results were found when Motraghi and Marinov (2012) evaluated the inclusion of freight train services within a urban metro system.

\subsubsection{Hybrid Simulation-Optimization Models}

Simulation can be combined with optimization techniques to enhance the decision-making process and the approaches are often named "hybrid" simulation-optimization (Abril et al., 2008; Crainic, Perboli and Rosano, 2018). In the rail context, Abril et al. (2008) point out that optimization methods usually obtain a desired train schedule which is validated by means of simulation. There are 3 ways simulation and optimization can interact (Crainic, Perboli and Rosano, 2018): (a) simulation with optimization-based iterations (SOI), when one or more complete optimization procedures are performed in a simulation run; (b) alternate simulationoptimization (ASO): meaning that simulation and optimization run alternately more than once, 
with feedback loops in each iteration; and (c) sequential simulation-optimization (SSO): when these methods run after each other, only once, with either optimization following simulation or the opposite.

Fioroni (2008), based on improvements of previous works (Franzese, Fioroni and Botter, 2003; Fioroni et al., 2005), provided a model to validate empty car loading distribution of cyclic trains in a major Brazilian rail network. In the validation process, the coefficients of a distribution equation were taken as decision variables in order to approximate the simulated tonnage transported to real-world target values. Both an optimization procedure within the simulation (SOI approach) and an ASO procedure were tested against the option of random choice of distribution. The first two approaches presented satisfactory results, with mean error below 5\%, meanwhile random choice was $12 \%$ far from real values. Camargo and Barbieri (2012) analyzed operational policies involving queueing disciplines in loading/unloading facilities and empty railcar distribution. A heuristic approach was used in an ASO framework in order to choose a subset of combinations to provide a near-optimal operational policy. The authors found that proposed prioritization rules performed better than conventional rules (such as FIFO or random choice) and also that the unloading facility in the port represent the bottleneck of the system.

Behiri, Belmokhtar-berraf and Chu (2018) used a simulation model to verify the results of a schedule provided by a Freight-Rail Scheduling problem. The main objective was to evaluate the addition of freight trains in a passenger rail network in terms of train waiting times and space required by goods to be loaded/unloaded in stations by a SSO approach. The authors found only $2 \%$ increase in average travel time when comparing no demands to many (100) demands.

Layeb et al. (2018) formulated a Service Network Design optimization model in a multimodal perspective, including roadway, railway and waterway modes, using more realistic travel time inputs with skewed and multimodal distributions. In an ASO procedure, a multi-objective function considering transport costs, delay and $\mathrm{CO}_{2}$ emissions was minimized. The authors managed to obtain on-time delivered services in more than $90 \%$ of times within reasonable computational time (less than or equal to $60 \mathrm{~min}$ ).

\subsection{Summary and Timeliness of the Research}

A summary of the simulation network models discussed is chronologically shown in Table 1. The second column indicates whether or not dispatching rules (DR) were considered in the 
model. This is an important part of railway modeling as a consequence of the exponential relationship between traffic volume and train delays that occurs mainly in single lines. Some models (Camargo and Barbieri, 2012; Layeb et al., 2018) use historic travel times without considering this feature and then are not appropriate to evaluate increase in train volume. Columns 3 to 7 indicate if and how some types of features were used in the model. Columns 3 to 5 refer to infrastructural parameters in line tracks (LT), loading facilities (LF) and unloading facilities (UF), meanwhile columns 6 and 7 are related to railway vehicles (VE) and operational policies (OP). Cells marked as " $F$ " means that, though modeled, values remained fixed, i.e. they were parameters in the simulation. "SWI" stands for simple what-if investigation, meaning that few scenarios were simulated with no concern with either experimental design approaches or optimization modeling. "DOE" means that a design-of-experiments method was carried out and "OPT" indicates that a hybrid simulation-optimization was used (either SOI, ASO or SSO). Cells in blank means that such features were not modeled at all. Finally, the last two columns in the table indicate if closed-loop trains were represented and the location of the real-world system modeled, respectively.

Table 1 - Characterization of rail modeling approaches surveyed

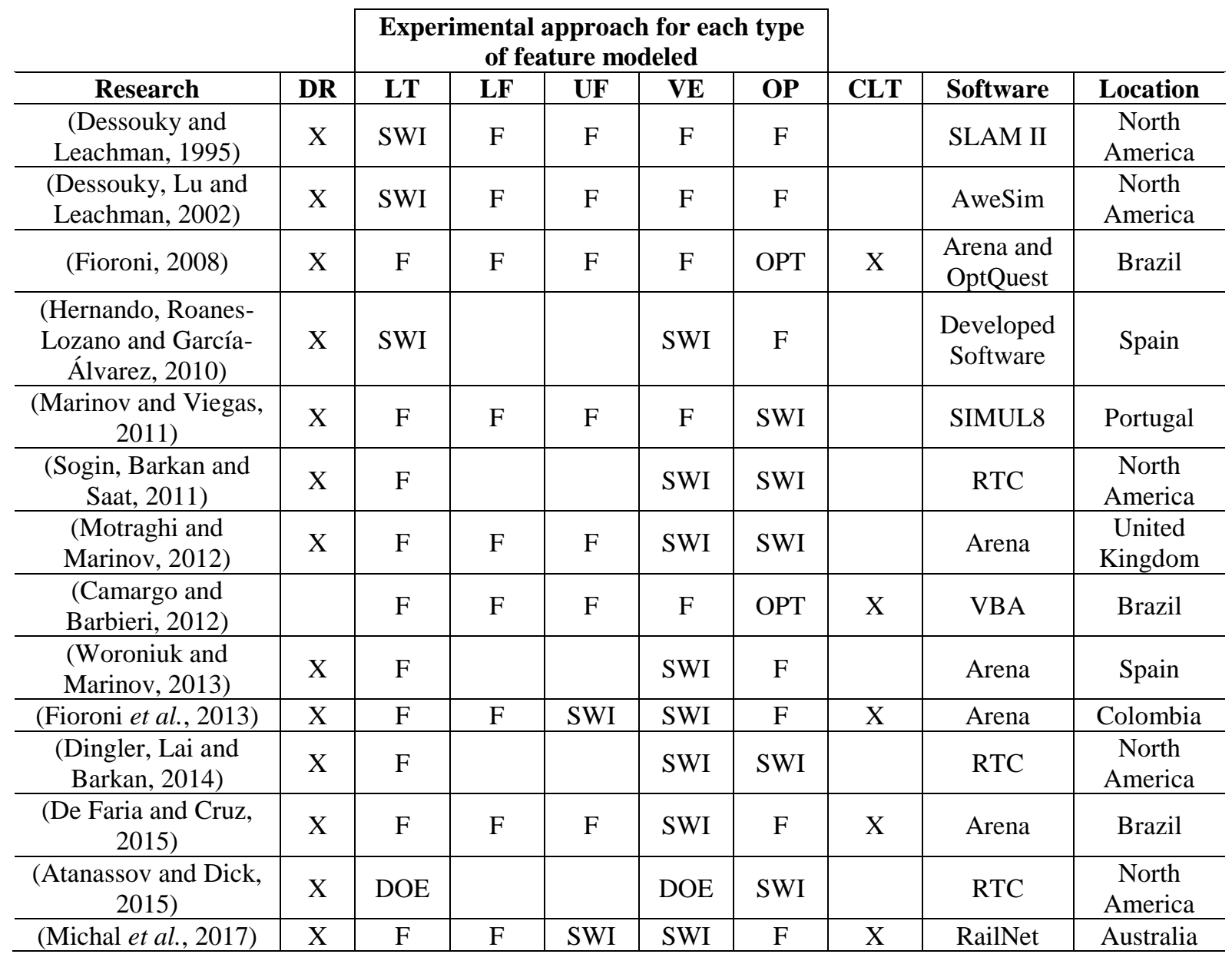




\begin{tabular}{c|c|c|c|c|c|c|c|c|c}
\hline $\begin{array}{c}\text { (Behiri, Belmokhtar- } \\
\text { berraf and Chu, 2018) }\end{array}$ & X & F & F & F & F & OPT & & Arena & France \\
\hline (Layeb et al., 2018) & & F & F & F & F & OPT & & $\begin{array}{c}\text { Arena and } \\
\text { OptQuest }\end{array}$ & $\begin{array}{c}\text { Central } \\
\text { Europe }\end{array}$ \\
\hline Paper Proposal & $\mathbf{X}$ & OPT & OPT & OPT & OPT & F & $\mathbf{X}$ & $\begin{array}{c}\text { Arena and } \\
\text { OptQuest }\end{array}$ & Brazil \\
\hline
\end{tabular}

The last line of Table 1 presents this paper's modeling proposal. We developed a hybrid simulation-optimization model (in an ASO framework) using software Arena to simulate train movements and activities and OptQuest to perform the optimization analysis. We proposed a minimization of capital costs with respect to decision variables consisting of line tracks (single/double lines, number of lines in classification yards), loading and unloading operations (number of yard lines, number and capacity of loading/unloading equipment) and vehicles (number of trains). Unlike the majority of the models, we aim at aiding a decision-making process in strategic level.

Given the research background in simulation network models, the current work is relevant for the following reasons:

(a) Most research focus on investigating the impact of train volume and heterogeneity (VE) or operational policies (OP). Whenever infrastructure variables were considered, authors analyzed few what-if scenarios or, alternatively, only one type of infrastructure variable in a DOE framework (Atanassov and Dick, 2015).

(b) Although the impact of infrastructure alternatives on operational performance was tested, there were no concern about the costs involved. This fact is stressed by Dessouky and Leachman (1995) in the results of their paper. Since capital outlay is exceedingly costly in the rail mode, it would be more appropriate to carry out this task within a costbenefit framework.

(c) Loading and unloading facilities are rarely investigated, if ever modeled. These are important rail nodes that, when disrupted, may cause upstream delays and downstream idle periods in line tracks. Operational performance of cyclic trains is specially harmed when this occurs.

(d) Few models consider trains running in a closed-loop fashion. The economy of scale appeal in transportation of iron ore, coal, grains and other commodities compels these freight trains to follow an improvised operation pattern (or semi-structured schedules, at best). Cyclic trains make up more than $80 \%$ of Brazilian railway transport, but it is also present in other freight networks such as Australia (Michal et al., 2017), North 
America and Western Europe (Marinov and Viegas, 2011). Despite the benefits of structured-fixed schedules, this operational production pattern requires high level of management standardization that has not yet been fully implemented.

\section{METHOD}

\subsection{System Description}

The West-East Integration Railroad (Ferrovia de Integração Oeste Leste - FIOL) is a heavy haul broad-gauge Brazilian railroad in the Northeast and Center-West regions of Brazil (Figure 1). FIOL was conceived to transport iron ore, grains and ethanol from the countryside to the South Port in the town of Ilheus. It spans $1527 \mathrm{~km}$ of tracks, of which $1008 \mathrm{~km}$ are under construction - from the town of Barreiras ( $\mathrm{km} \mathrm{519)}$ to the town of Ilheus (km 1527) - and 519 $\mathrm{km}$ awaits environmental clearance - from the town of Figueirópolis $(\mathrm{km} 0)$ to the town of Barreiras (km 519). The most important loading sites are located in Caetité (km 918) and Brumado (km 1145), for iron ore, and Combinado (km 349), Barreiras (km 519) and Correntina ( $\mathrm{km}$ 703), for grains (mainly soybean and corn) and ethanol. It is also expected that some grain trains access FIOL from the North South Railroad (Ferrovia Norte Sul - FNS). Although FIOL also crosses the Center Atlantic Railroad (Ferrovia Centro Atlântica - FCA), the latter is a narrow-gauge railroad.

Figure 1 - Map of FIOL



The mainline route in FIOL is single-track, i.e. trains in opposite directions cross each other at passing sidings (or simply "sidings"), where a parallel line exists with length larger than the longer train in that route. Train operation is based on an absolute block signaling system with 
2 section blocks between sidings. It is important to mention that only one train at a time is allowed to travel along each block. Maximum train speed is $60 \mathrm{~km} / \mathrm{h}$ for loaded trains and 70 $\mathrm{km} / \mathrm{h}$ for empty trains and no passenger service is envisaged to run in FIOL. Then, there is no concern about priority heterogeneity in this railroad.

\subsection{System Modeling and Simulation}

The transport of iron ore plays an important role in the feasibility of FIOL. It is expected that $70 \%$ of total freight revenues comes from the transport of such commodity in early operational phase (Brasil, 2010). For this reason, the scope of the model is limited to train traffic in $539 \mathrm{~km}$ of tracks between Caetité and Ilhéus, including train activities in loading and unloading terminals. The construction of this stretch of railroad achieved $80 \%$ of physical progress (Brasil, 2019) and, when completed, further investments in nonexistent loading/unloading terminals and vehicles are going to be necessary. Although upstream train movements and activities from Figueirópolis to Caetité were not modeled, the expected flow from these trains within the region modeled were considered.

The iron ore rail freight is conceived based upon a closed-loop system. As mentioned before, cyclic trains are unitarian trains with a fixed number of railcars that run continuously through a closed-circuit comprising loading, moving loaded to a port rail terminal, unloading and moving empty to a loading terminal next to the mines. These trains are subject to several interferences from both interaction with other trains and disruptions in loading and unloading processes.

To model this system, we used a decomposition approach, breaking down the rail network into 3 components: rail lines, rail loading terminal and rail unloading terminal. Marinov and Viegas (2011) point out that this is a practical approach that has already proven its credibility. By bringing these pieces together the railway network can be precisely modeled. The conceptual models from these three parts are described in sections 3.2.1 to 3.2.3.

\subsubsection{Rail Line}

The $539 \mathrm{~km}$ of tracks between Caetité and Ilhéus consists of single lines interleaved by 19 sidings. A typical iron ore train consists of 2 locomotives and 140 gondola railcars. In order to fit these trains, sidings between Caetité and Ilhéus have $2023 \mathrm{~m}$ length. The conceptual model for train movement in rail lines has the main objective to the decide whether to halt or allow for each train to move to the next section of track. The decision of halting a train is made in order to avoid a frontal collision, a rear collision or a deadlock. According to Pachl (2007), "a 
deadlock is a situation in which a number of trains cannot continue along their path at all because every train is blocked by another one". A typical deadlock situation is depicted in Figure 2, where no trains can move forward in their routes.

Figure 2 - Deadlock illustration

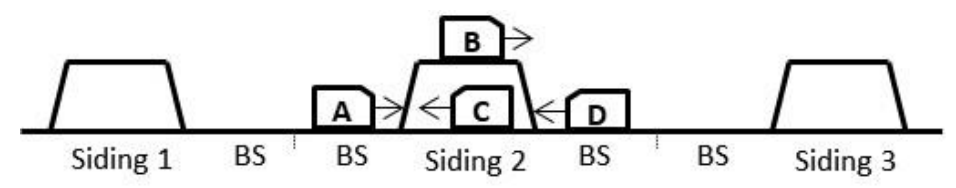

The decision rules to avoid such situations are usually tackled by discrete event routines (Medanic and Dorfman, 2002; Fioroni et al., 2013). In each discrete step an algorithm within the simulation checks if a deadlock situation is going to occur. In the case of FIOL, every time a train requires an upcoming movement, the routine described in the flowchart of Figure 3 must be checked. We allow for a line to be either single or double by creating a user-defined vector containing 1's or 2's, respectively, for each block section from Caetité to Ilheus. Thus, the model can flexibly handle different situations of track configuration. 
Figure 3 - Rail line model (Dispatching Rules)

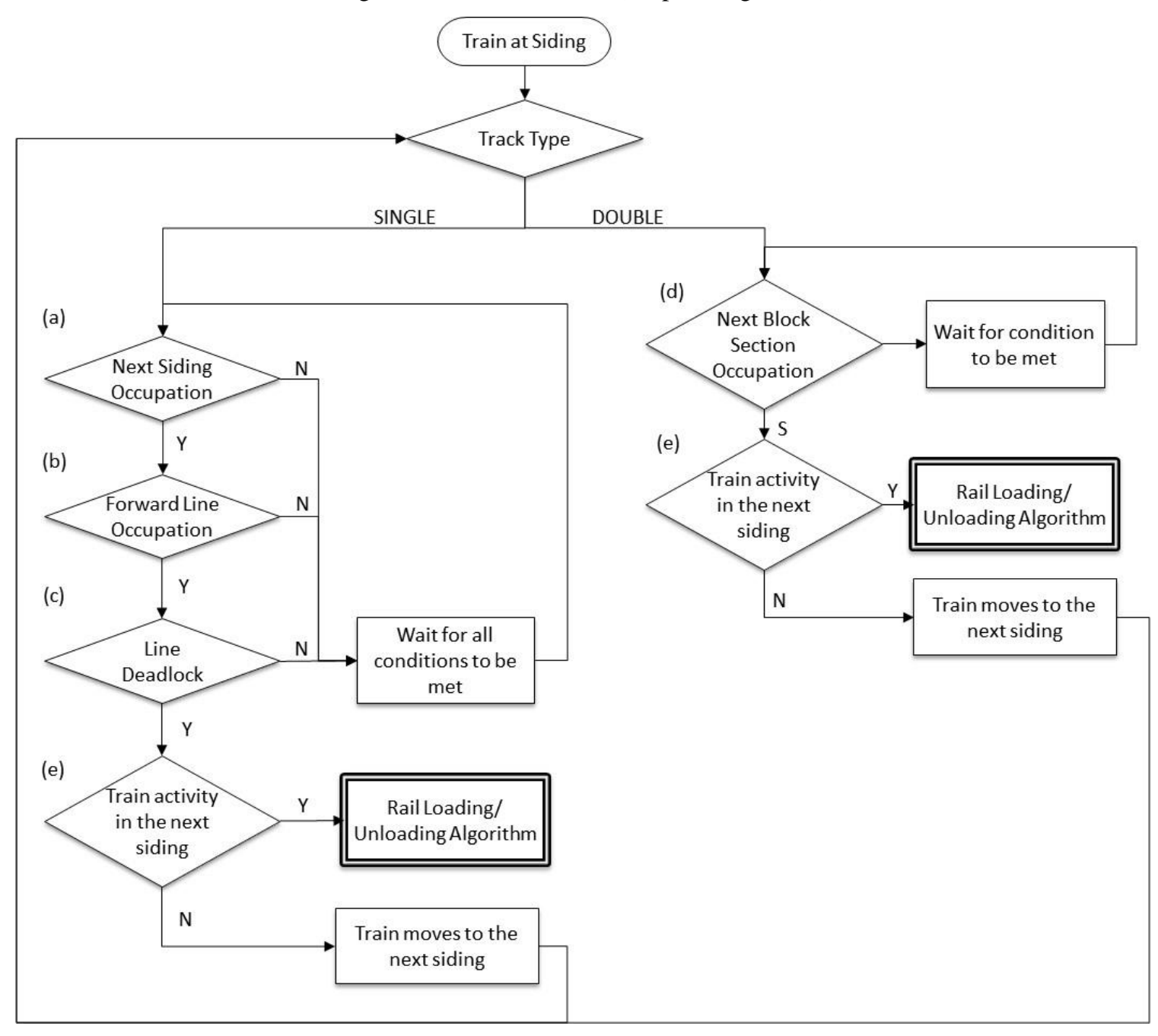

In the case of a single line, 3 conditions have to be simultaneously met in order to allow for the train movement, i.e. the train can only occupy the next section if (Fioroni, 2008):

(a) Next siding occupation: (both lines are empty) OR (there is only one line occupied in the opposite direction). It is worth mentioning that no overtakings occur in sidings (only crossings) as we are modeling a homogeneous rail network with respect to priority and speed.

(b) Forward line occupation: (no block sections of the line have trains in opposite direction) AND (next block section is available).

(c) Line Deadlock: the number of trains running in the same direction of the requester train between its section and the section of the next train in the opposite direction is less than the number of sidings within this region minus 1 .

The situation on condition (c) is clearly depicted in Figure 4. If train D is allowed to enter the line between sidings 2 and 3 in moment iii), a deadlock will occur (Figure 2). Note that under 
this scenario, there is 1 train between D (requester train) and train B (next train in the opposite direction with respect to D) whereas the region comprised between $\mathrm{D}$ and $\mathrm{B}$ has 2 sidings. Thus, $\mathrm{D}$ is not allowed to move forward and has to wait for this condition to be met.

Figure 4 - Conflict solved by the proposed algorithm

i) Conflict imminence

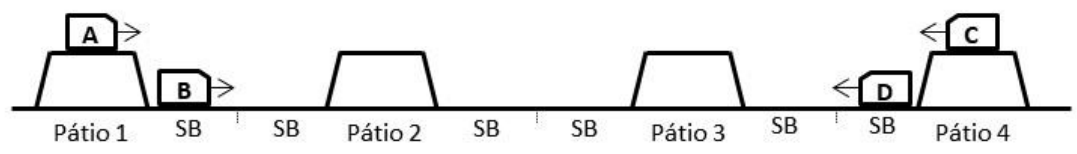

ii) Train $\mathrm{C}$ access siding 3 immediately before train $\mathrm{B}$ access siding 2

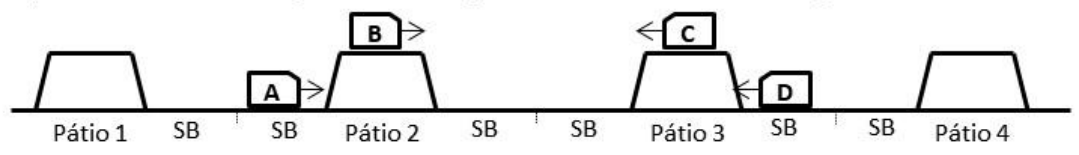

iii) Train $\mathrm{D}$ waits for condition (c) to be met

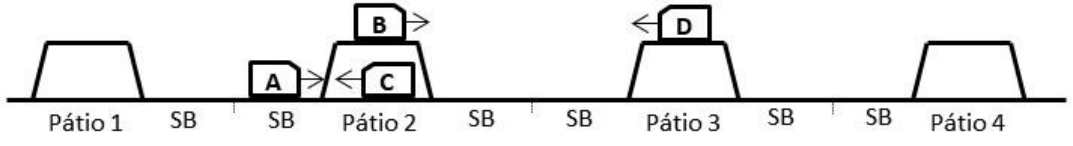

iv) Train A waits for clearance in the next section

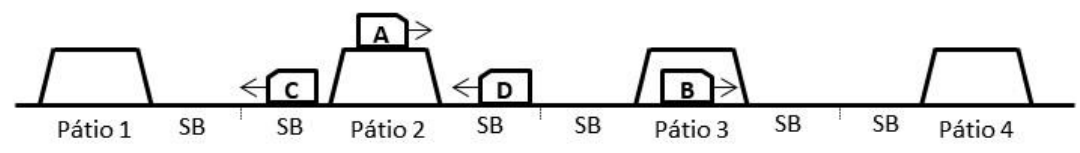

v) Conflict solved for all trains

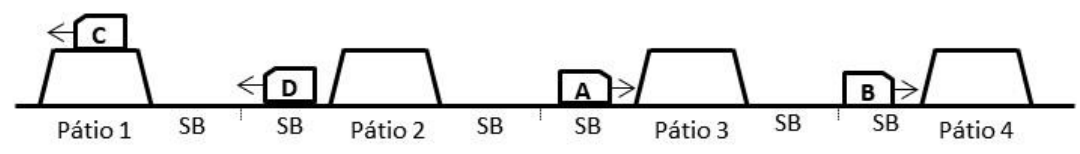

Before allowing the movement, the routine checks if the requester train is supposed to enter a loading or unloading area in the next siding (e). If so, the current model calls another model (relative to either rail loading terminal or rail unloading terminal) to seize a specific line in terminal and the train proceed to the movement. Note also that if there is a double line ahead, the only concern is about the occupation of the next block section (d).

The decision-making process is made by analyzing a dynamic vector that corresponds to the current state of occupation of all block sections in the system. "0", "1" and "2" indicate no occupation, occupation in the loaded direction (mine to port) and occupation in the empty direction (port to mine), respectively. This value can also be equal to " 3 ", when a siding is occupied with 2 trains in opposite directions $(2+1)$.

Once the movement is authorized, the train releases a block section and seize the forward one, changing the values of the dynamic vector relative to these section blocks. Trains carry 
attributes related to the direction of travel (" 1 " for loaded direction and "2" for empty direction). This attribute is changed as soon as trains leave terminals. As they seize (release) a section, the vector slot relative to this section is added (subtracted) by this attribute value. Therefore, it is possible for all trains in a discrete step in time move onwards or wait for an opportunity to do so.

\subsubsection{Rail Loading Terminal}

There are 2 sites for iron ore loading in FIOL, namely Caetité (km 989) and Brumado (km 1145). In both places, trains are received in an arrival/departure yard with 2 lines in the vicinity of a siding, according to the illustrative scheme in Figure 5. Then, the locomotive driver is replaced by a yard locomotive driver and the train waits for authorization to access the balloon loop line where there is an iron ore silo loading system. After authorization, the yard locomotive driver rides the train in constant speed through the balloon loop while the railcars are loaded under the silo. Once the loading operation is completed, the yard train driver requires access to a line in the arrival/departure yard. Then, the railcars are examined, the yard train driver is replaced by a new train driver which performs train breaking tests. Finally, the loaded train requires authorization to the operations control center to travel back to the port.

Figure 5 - Illustrative scheme of iron ore loading terminal next to FIOL

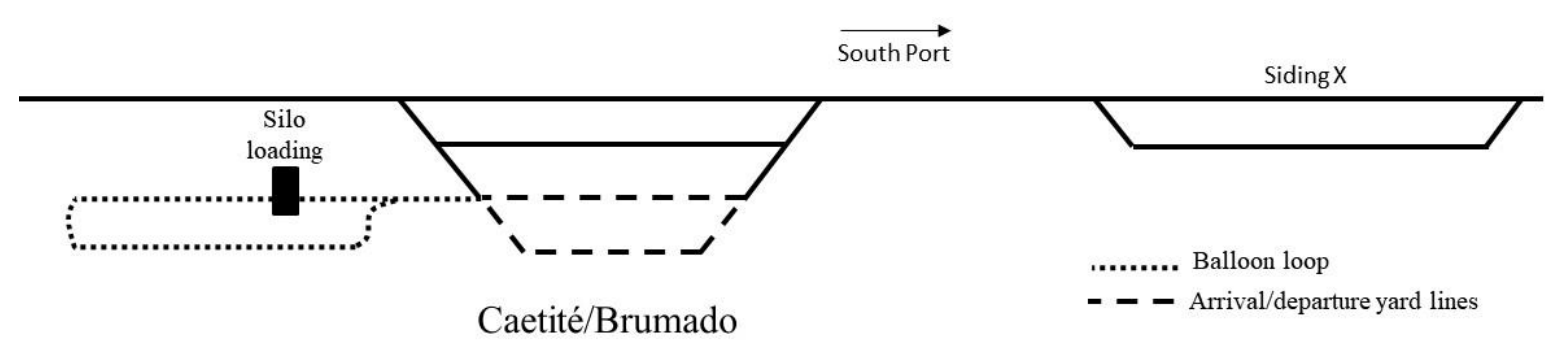

To prevent a deadlock from occurring in the rail loading terminal the model depicted in Figure 6 was developed. The first verification starts with the unloaded train located in a siding " $X$ " right before the rail loading terminal. 
Figure 6 - Rail loading terminal model


Let $L$ be a user-defined value indicating the number of lines in the arrival/departure yard. Similar to the logic described in section 3.2.1, there are also dynamic variables indicating the current state of occupation of these lines. $O_{l}$ and $O_{e}$ corresponds to the number of lines occupied in the "loaded" direction (trains newly loaded) and the number of lines occupied in the "empty" direction (trains waiting to access the balloon loop), respectively. Then, the decision points in the algorithm are described below:

(a) Entry deadlock: the empty train in siding "X" will be granted access to the arrival/departure yard if and only if $\left(L-O_{l}-O_{e}\right) \geq 1$ AND $\left(L-O_{e}\right) \geq 2$, meaning that there must be at least 1 line available and if there is occupation in the same direction of the requester train (empty direction), the total number of lines in the arrival/departure yard must be 2 units higher than the number of trains occupying the yard in that direction.

(b) Balloon loop access: trains only enters the balloon loop if there is a line with a silo loading system available.

(c) Exit deadlock: the loaded train in the balloon loop line can only access a line in the arrival/departure yard if and only if $\left(L-O_{l}-O_{e}\right) \geq 1$ AND $\left(L-O_{l}\right) \geq 2$, i.e. there 
must be at least 1 line available and if there is occupation in the same direction of the requester train (loaded direction), the total number of lines in the arrival/departure yard must be 2 units higher than the number of trains occupying the yard in that direction.

Note again that the model rules allow for different number of lines in the arrival/departure yard and more than one silo loading system without loss of generality.

\subsubsection{Rail Unloading Terminal}

This model is executed after a train at siding " $\mathrm{Y}$ " is granted access to an arrival/departure yard with 4 lines, right before the tracks inside the port area, as shown in Figure 7. This arrival/departure yard is linked to the port through a $4 \mathrm{~km}$ double-track access line (AL) that branches into 2 lines, one for general cargo trains (mainly grains and ethanol) and other for iron ore trains. For the latter there is a reception/formation yard from where the train access a balloon loop with a car dumper equipment for unloading operation. If the car dumper is idle, trains arriving from the arrival/departure yard go directly to the car dumper. Otherwise, they have to stop at a reception line (RL) and wait until the car dumper is released. When the train is positioned at the car dumper, the locomotives are cut and moved to the vehicle workshop (VW) for inspection routines followed by fueling. While the railcars are unloaded, yard agents also inspect railcars for failures, marking them as defective if applicable.

Figure 7 - Illustrative scheme of rail unloading terminal and nearby FIOL tracks

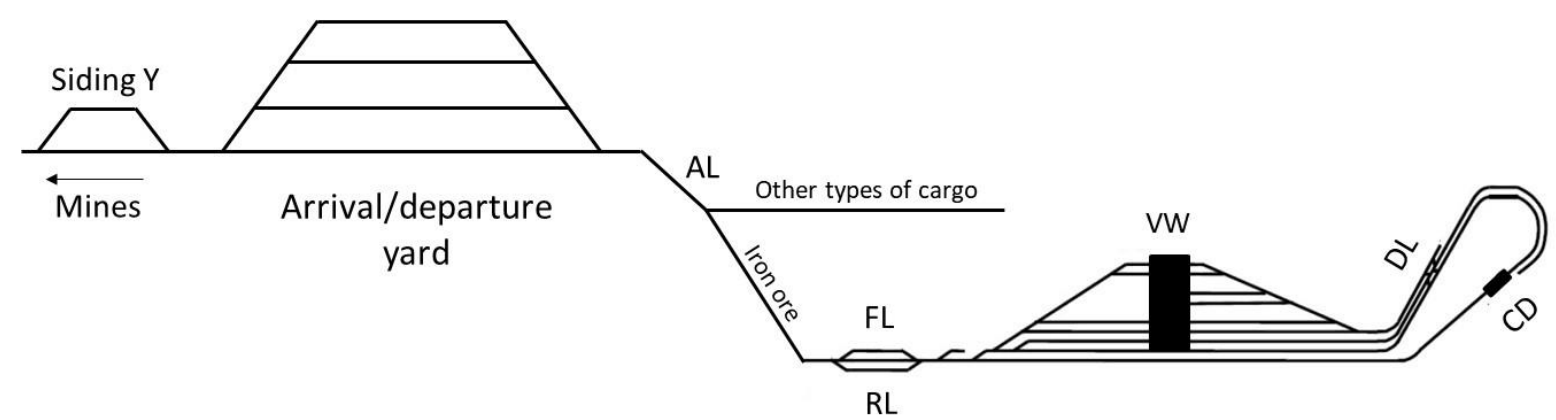

A maneuver locomotive is positioned ahead of the car dumper and takes the railcars to a formation line (FL). Defective railcars are cut from the train and stored in a defective railcar line (DL) for later maintenance. To complete the 140-railcar block, fixed-up railcars from the vehicle workshop are moved by the maneuver locomotive to the formation line. After that, the locomotives are assembled to the railcar block, train brakes are tested and the train driver require access to travel back to the rail loading yard. 
The abovementioned process is performed according to the conceptual model described in the flowchart of Figure 8.

Figure 8 - Rail unloading terminal model
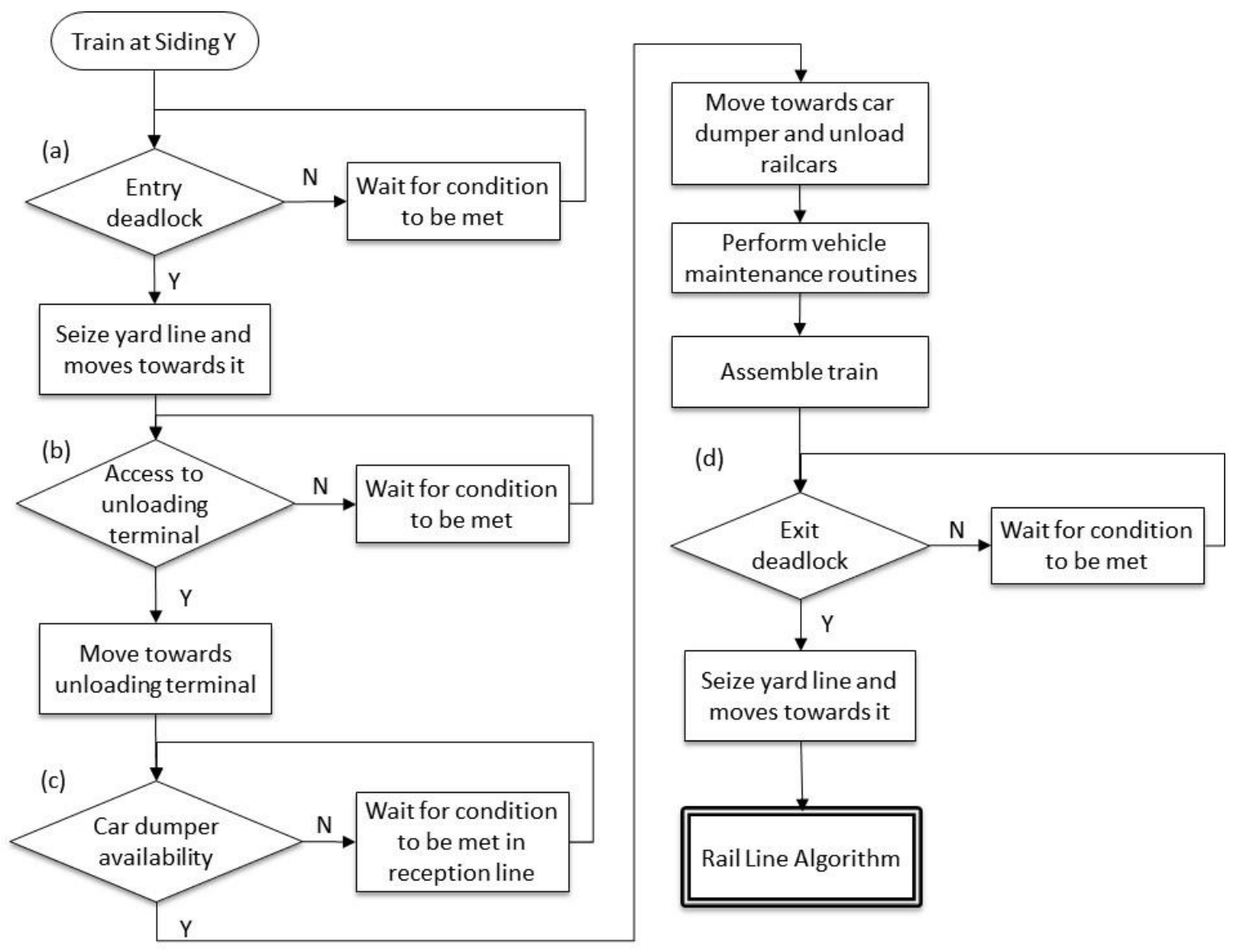

Similar to the model described in Section 3.2.2, let $U$ be a user-defined value indicating the number of lines in the arrival/departure yard next to the unloading terminal. Also, $B_{l}$ and $B_{e}$ are variables representing the number of lines occupied in the "loaded" direction (trains requiring access to the port) and the number of lines occupied in the "empty" direction (trains returning to the rail loading terminals), respectively. Then, the decision points in the algorithm are described below:

(a) Entry deadlock: the empty train in siding "Y" will be granted access to the arrival/departure yard if and only if $\left(U-B_{l}-B_{e}\right) \geq 1$ AND $\left(U-B_{l}\right) \geq 2$, meaning that there must be at least 1 line available and if there is occupation in the same direction of the requester train (loaded direction), the total number of lines in the arrival/departure yard must be 2 units higher than the number of trains occupying the yard in that direction. 
(b) Access to unloading terminal: (access line is available) AND (formation line is available).

(c) Car dumper availability: verifies if there is a car dumper line available. If so, train access car dumper directly. Otherwise, train must wait in the reception line.

(d) Exit Deadlock: the unloaded train in the formation line can only access a line in the arrival/departure yard if and only if $\left(U-B_{l}-B_{e}\right) \geq 1$ AND $\left(L-B_{e}\right) \geq 2$, i.e. there must be at least 1 line available and if there is occupation in the same direction of the requester train (empty direction), the total number of lines in the arrival/departure yard must be 2 units higher than the number of trains occupying the yard in that direction

The rules can be applied to any value of $U$ without loss of generality. For the sake of simplicity, we do not consider maintenance aspects of the system, i.e. the time elapsed from the end of unloading operation to the formation of the train is considered as if all railcars are not defective.

\subsubsection{Simulation}

The conceptual models from previous sections were implemented in Arena, developed by Rockwell Software, the most used simulation tool in supply chain and logistics (Oliveira, Lima and Montevechi, 2016). The computational model is developed by attaching command blocks to the work area representing pre-defined actions in the SIMAN language. The software allows for an intuitive development environment that facilitates the construction of models and their evaluation by standardized reports and experimental routines.

All input values of the model were collected from operational reports from both FIOL (Brasil, 2010) and South Port (Bahia, 2011). Time values include but are not limited to: loading and unloading times, travel times between sidings, inspection and breaking tests and licensing authorization. As these values are deterministic, we carried out a simulation in a dynamicdeterministic fashion.

The entities of the model are the trains, inserted by CREATE blocks. Two CREATE blocks generate a pre-defined number of cyclic iron ore trains at Caetité and Brumado that move through the system until the end of simulation. Eight CREATE blocks are placed at the borders of the system (4 in Caetité and 4 in Ilhéus) to generate the volume associated with grain and ethanol trains in both directions. The times between arrivals for these eight CREATE blocks were defined based on the generation of trains from Figueirópolis, Combinado, Barreiras and Correntina. As soon as these trains hit the opposite frontier relative to where they were created, a DISPOSE block remove them from the system. 
The trains move through the system between geographically separated locations (represented by STATION blocks) using ROUTE blocks. They obey the model logic and demand resources (such as rail lines and equipment like silos and car dumpers) as soon as they are available. After being used, the resource is released and becomes available for another train to use it. All this process is performed by using SEIZE, DELAY and RELEASE blocks. When these resources are busy or the trains are not allowed to use them in order to avoid an accident or a deadlock, they must wait for a favorable condition. In these cases, they wait in the queue of either a SEIZE block or a HOLD block, the latter being able to deal with more complex logical decisions.

Important times are recorded such as waiting times, time elapsed within terminals as well as the whole iron ore cycle (load $\rightarrow$ move $\rightarrow$ unload $\rightarrow$ move). It is also recorded the total tonnage delivered in port for a specific period by RECORD blocks that store this quantity in a tally variable.

The system works in a non-terminal fashion, i.e. it starts in a specific period of time and runs indefinitely. Since the system starts empty, the first trains move throughout their routes without facing conflicts with other trains, biasing down the average iron ore cycle time. Accordingly, it was defined a warm-up period of 200 hours in which the results are removed from the simulation. Thus, the system is analyzed from the stationary state onwards. As the simulation is deterministic it was carried out a unique replication of 1 month to produce and analyze the outcomes.

\subsection{Optimization Model}

The proposed optimization model was motivated by the hypothesis that the current set of projected infrastructure parameters does not provide an operational efficiency that meets the overall mining production from Caetité and Brumado. As soon as the construction of FIOL finishes, it will be necessary to incur in supplementary capital costs related to rail terminals and vehicles. Then, some interventions considering trackage configuration, quantity and capacity of equipment and fleet sizing are tested in order to achieve this goal at minimal cost. The model is defined as follows:

$$
\begin{aligned}
& \text { Min } Z=R V+L D+S L+Y L+U T+C D+Y U, \quad \text { s.t.: } \\
& P_{C A E} \geq G_{C A E} \\
& P_{B R U} \geq G_{B R U} \\
& S_{C A E}^{I}+S_{C A E}^{I I}+S_{C A E}^{I I I} \geq 1
\end{aligned}
$$




$$
\begin{aligned}
& S_{B R U}^{I}+S_{B R U}^{I I}+S_{B R U}^{I I I} \geq 1 \\
& D_{P 1}^{I}+D_{P 1}^{I I} \geq 1 \\
& D_{P 2}^{I}+D_{P 2}^{I I} \geq P \\
& 0 \leq S_{C A E}^{j} \leq 2, \forall j \\
& 0 \leq S_{B R U}^{j} \leq 2, \forall j \\
& 0 \leq D_{P 1}^{k} \leq 2, \forall k \\
& 0 \leq D_{P 2}^{k} \leq 2, \forall k \\
& 6 \leq T_{C A E} \leq 9 \\
& 8 \leq T_{B R U} \leq 12 \\
& 2 \leq L_{C A E} \leq 5 \\
& 2 \leq L_{B R U} \leq 5 \\
& 4 \leq U \leq 7 \\
& S_{C A E}^{j}, S_{B R U}^{j}, \forall j ; D_{P 1}^{k}, D_{P 2}^{k}, \forall k ; T_{C A E}, T_{B R U}, L_{C A E}, L_{B R U}, U \in Z^{+} \\
& B_{i} \in(0,1), \forall i \text { e } P \in(0,1)
\end{aligned}
$$

In the objective function (1), $Z$ is the sum of all supplementary investments to be made in this rail network. It consists of the following items:

a) Rail Vehicles $(R V)$ :

$$
\left(T_{C A E}+T_{B R U}\right)\left(140 C_{r c}+2 C_{l c}\right)
$$

Where $T_{C A E}$ e $T_{B R U}$ are decision variables representing the number of trains formed in both Caetité and Brumado. $C_{r c}$ and $C_{l c}$ are the purchasing costs of a gondola railcar and a GE Dash 9 locomotive, respectively, both in Brazilian Reais/unit (R\$/unit);

b) Line Duplication $(L D)$ :

$$
\sum_{i=1}^{19} B_{i} l_{i} C_{m l}
$$

Where $B_{i}$ is a binary decision variable indicating whether the line $i$ between adjacent sidings has to be duplicated (1) or not (0). $l_{i}$ is the length of this line (in $\mathrm{km}$ ) and $C_{m l}$ is the average cost of mainline duplication (in $\mathrm{R} \$ / \mathrm{km}$ ).

c) Silo Loading System $(S L)$ : 


$$
\sum_{j=I}^{I I I}\left(S_{C A E}^{j}+S_{B R U}^{j}\right)\left(C_{s}^{j}+l_{s} C_{y}\right)
$$

Where $S_{C A E}^{j}$ e $S_{B R U}^{j}$ are decision variables corresponding to the number of silo loading systems of type $j$ in the rail loading terminals of Caetité and Brumado, respectively. There are 3 types of system depending on the capacity of the equipment used: type I loads 4000 t/h (4.32 h/train), type II loads 6000 t/h (2.88 $\mathrm{h} /$ train) and type 3 loads $16000 \mathrm{t} / \mathrm{h}(1.08 \mathrm{~h} /$ train $)$. Also, $C_{S}^{j}$ is the cost of silo equipment of type $j, l_{s}$ is the length of the balloon loop of the silo (in $\mathrm{km}$ ) and $C_{y}$ is the average cost of yard lines (in $\mathrm{R} \$ / \mathrm{km}$ ).

d) Arrival/departure yard in the loading rail terminal $(Y L)$ :

$$
\left(L_{C A E}+L_{B R U}\right)\left(l_{y l} C_{y}+2 C_{s W}\right)
$$

Where $L_{C A E}$ and $L_{B R U}$ are decision variables representing the number of lines in the arrival/departure yard in the loading terminal of Caetité and Brumado, respectively. $l_{y l}$ is the length of each line (in $\mathrm{km}$ ), $C_{y}$ is the average cost of yard lines (in $\mathrm{R} \$ / \mathrm{km}$ ) and $C_{s w}$ is the cost of a railroad switch (in $\mathrm{R} \$ / \mathrm{unit}$ ).

e) Unloading Port Terminal (UT):

$$
(P+1) C_{p}
$$

Where $P$ is a binary decision variable relative to the existence of an additional unloading port terminal, consisting of a stacker-reclaimer system, conveyor belts, civil works and ancillary equipment. $P$ is equal to 1 if an additional terminal has to be implemented and 0 otherwise. $C_{p}$ is the capital cost of this unloading port terminal ( $\mathrm{R} \$ /$ terminal).

f) Car Dumper System $(C D)$ :

$$
\sum_{k=I}^{I I}\left(D_{P 1}^{k}+D_{P 2}^{k}\right)\left(C_{d}^{k}+l_{d} C_{y}\right)
$$

Where $D_{P 1}^{k}$ and $D_{P 2}^{k}$ are decision variables defining the number of car dumper systems (i.e. a car dumper equipment and a balloon loop) of type $k$ in the original unloading port terminals (P1) and the additional terminal (P2), respectively. $k=$ I represents a simple car dumper, with capacity of $4000 \mathrm{t} / \mathrm{h}(4.32 \mathrm{~h} / \mathrm{train})$ and $k=I I$ refers to a double car dumper, with capacity of $9400 \mathrm{t} / \mathrm{h}(2.16 \mathrm{~h} / \mathrm{train})$. $C_{d}^{k}$ is the cost of a car-dumper equipment of type $k$ (in $\mathrm{R} \$ /$ unit) and $l_{d}$ is the length of the balloon loop (in $\mathrm{km}$ ). 
g) Arrival/departure yard next to the unloading rail terminal $(Y U)$ :

$$
U\left(l_{y u} C_{y}+2 C_{s w}\right)
$$

Where $U$ is the decision variable relative to the number of lines in the arrival/departure yard next to the port and $l_{y u}$ is the length of a line in this terminal.

The cost values above $(C$.) were gathered from the operational reports mentioned before (Brasil, 2010; Bahia, 2011) and surveys conducted with the Brazilian National Agency of Land Transport and the commercial department of the equipment manufacturing company Thyssenkrupp. As these nominal values did not correspond to the same moment at time, they were adjusted for inflation to the base year of 2019.

The inequalities in (2) and (3) guarantee that the monthly iron ore delivered in port, $P_{C A E}$ and $P_{B R U}$, are greater than or equal to pre-defined goals $G_{C A E}$ and $G_{B R U}$, respectively. Next, the constraints (4) to (7) assure that all trains are met by at list 1 silo system in their loading operations and by at least 1 car dumper system in their unloading port terminals. The ranges from (8) to (16) define a hyperspace of feasible solutions for the integer decision variables of the model. Finally, (17) and (18) define variables as either integer or binary, respectively.

As mentioned before, the approach to solve this problem is given by an alternate simulationoptimization (ASO) approach in which a search algorithm uses the results of a simulation trial in order to continually improve the solution. This model is solved using OptQuest, a commercial software provided by OptTek System Inc. OptQuest uses a combination of meta-heuristics like tabu search and scatter search along with neural networks for its search algorithm (Layeb et al., 2018). From an initial solution given by the user, it was defined a maximum number of iterations equal to 2000 to observe the evolution of the objective function.

\section{COMPUTATIONAL RESULTS AND ANALYSIS}

The model was validated by comparing the average cycle time of iron ore trains loading in Caetite given by the simulation to the results observed in previous operational studies (Brasil, 2010),for two production levels. The first production level accounts for only 6 iron ore trains loading in Caetité whereas the second includes other trains from Barreiras, Correntina and Combinado. The model produced satisfactory results with cyclic time differential of $3,54 \%$ in the first scenario and 1,33\% for the second one. The model was also verified with respect to the rules developed in sections 3.2.1 to 3.2.3, producing neither deadlocks nor insecure conditions. 


\subsection{Simulation of Baseline Scenario}

The baseline scenario consists of single tracks $\left(B_{i}=0, \forall i\right), 6$ trains loading in Caetité $\left(T_{C A E}=\right.$ 6), one silo loading system of type I for Caetité and Brumado $\left(S_{C A E}^{I}=S_{B R U}^{I}=1\right), 2$ lines for the arrival/departure yard in the loading terminal for Caetité and Brumado $\left(L_{C A E}=L_{B R U}=2\right)$, no additional unloading terminal $(P=0)$, a double car dumper system $\left(D_{P 1}^{I I}=1\right)$ and 4 lines in the arrival/departure yard next to the unloading terminal $(U=4)$.

The production goals for the mining companies is roughly $G_{C A E}=1.67$ million $\mathrm{t} / \mathrm{month}$ for Caetité and $G_{B R U}=2.92$ million t/month for Brumado. However, the number of trains for the latter was not investigated in early operational studies (Brasil, 2010) as new mining companies intended to join the supply chain afterwards. The impacts of the inclusion of trains loading in Brumado in the total tonnage delivered in port is shown in Figure 9.

Figure 9 - Plot of average cyclic time (primary axis) and iron ore delivered in port (secondary axis).



$=\mathrm{CAE}=\mathrm{BRU}-\mathrm{CAE}-\mathrm{BRU}$

According to the simulation outcomes no combinations among $T_{C A E}=6$ and $T_{B R U}=$ $\{0, \ldots, 12\}$ result in the desired production goals for both sites. To diagnose the causes, resources utilization was observed. In fact, for $T_{B R U} \geq 7$, the average occupation rate of the yard/departure lines and silo loading system of the rail loading terminal in Brumado is nearly 100\%. Consequently, trains loading in that site have to wait in the mainline of FIOL, provoking queues that harms overall cyclic times for all trains, including those loading in Caetité. The simulation animation in Figure 10 depicts this fact: 
Figure 10 - Queuing propagation from loading site in Brumado to FIOL

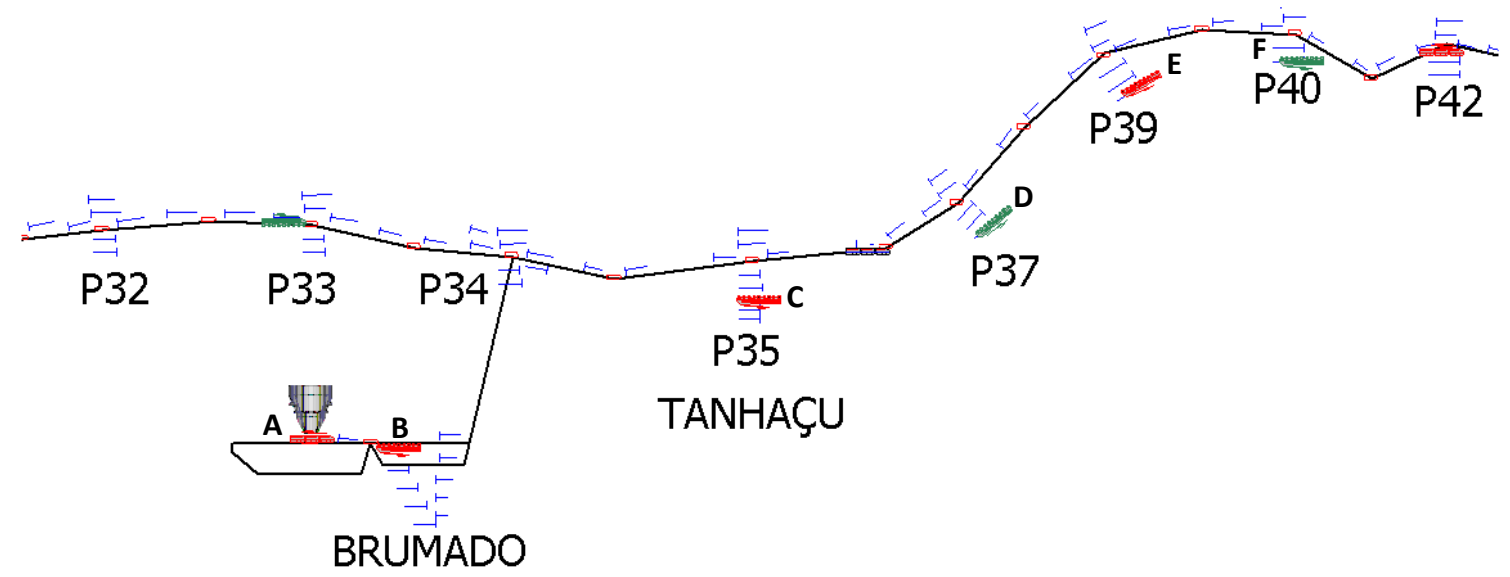

To tackle this situation, singly improving the loading operations in Brumado is not effective, as the queues are transferred to the port in a closed-loop system. The plot in Figure 11 shows how the daily average total time in queue decreases in the loading process to the detriment of an increase in the queues in port. It worth mentioning that this solution does not achieve the production goals for the mining companies.

Figure 11 - Queuing transfering between loading and unloading terminals

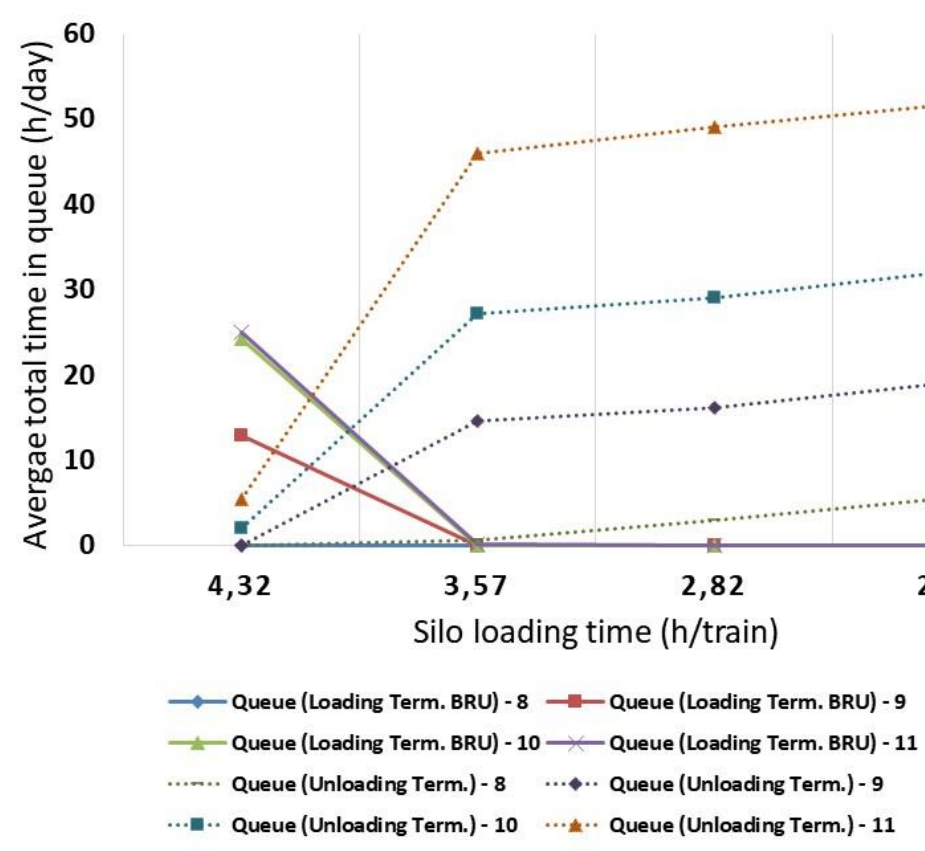

As one can see, the queues practically disappear for loading times lower than $3.57 \mathrm{~h} /$ train, causing an expressive rise in those queues related to the unloading terminal area. The reciprocal situation (queues transferred from unloading to loading operations) were also observed by solely improving the car dumper capacity. As the number of interventions is considerably high, we then solve the optimization model discussed in Section 3.3. 


\subsection{Simulation-Optimization Results}

The simulation-optimization model was run in an Intel Core i5 3.2 GHz processor, with 4.0 GB RAM. The initial solution provided was $T_{C A E}=6, T_{B R U}=9, P=1, S_{C A E}^{I}=S_{B R U}^{I}=D_{P 1}^{I}=$ $D_{P 2}^{I}=1, L_{C A E}=L_{B R U}=3, U=4$ and $B_{i}=0, \forall i$. All remaining decision variables were assigned the value 0 . The model was executed 3 times considering the current production goals for Caetité and Brumado (baseline scenario) along with 10\% and 20\% increase in such levels. The results are presented in Table 2:

Table 2 - Optimization results per production level

\begin{tabular}{c|c|c|c}
\hline Decision Variable & Baseline & $\mathbf{1 0 \%}$ Increase & 20\% Increase \\
\hline$S_{C A E}^{I}$ & 1 & 1 & 1 \\
$S_{C A E}^{I I}$ & 0 & 0 & 0 \\
$S_{C A E}^{I I I}$ & 0 & 0 & 0 \\
$S_{B R U}^{I}$ & 0 & 0 & 0 \\
$S_{B R U}^{I I}$ & 1 & 1 & 1 \\
$S_{B R U}^{I I I}$ & 0 & 0 & 0 \\
$D_{P 1}^{I}$ & 0 & 0 & 0 \\
$D_{P 1}^{I I}$ & 1 & 2 & 2 \\
$D_{P 2}^{I}$ & 0 & 0 & 0 \\
$D_{P 2}^{I I}$ & 0 & 0 & 0 \\
$T_{C A E}$ & 7 & 7 & 8 \\
$T_{B R U}$ & 9 & 2 & 11 \\
$L_{C A E}$ & 2 & 2 & 2 \\
$L_{B R U}$ & 2 & 4 & 2 \\
$U$ & 4 & 874 & 4 \\
Value of $Z$ & $\mathrm{R} \$ 784.420 .000,00$ & $\mathrm{R} 897.858 .000,00$ & $\mathrm{R} \$ 958.638 .000,00$ \\
Iteration of best $Z$ & 808 & & 863 \\
\hline
\end{tabular}

For the baseline scenario the solution provided by the search algorithm that satisfies the production goals at minimal (per category of decision variable) was:

a) Fleet sizing: 7 trains for Caetité $\left(T_{C A E}=7\right)$ and 9 trains for Brumado $\left(T_{B R U}=9\right)$.

b) Rail line: the duplication of lines was not considered at all $\left(D_{i}=0, \forall i\right)$.

c) Rail loading terminal: 1 silo loading system type I with 2 lines in the arrival/departure yard for Caetité $\left(S_{C A E}^{I}=1\right)$ and 1 silo loading system type II for Brumado $\left(S_{B R U}^{I I}=1\right)$. For both yard/departure yards, 2 lines suffice $\left(L_{C A E}=\right.$ $\left.L_{B R U}=2\right)$.

d) Rail unloading terminal: a single unloading terminal is enough to comply with the total production $(P=0)$, working with a double car dumper system $\left(D_{P 1}^{I I}=1\right)$ 
The fact that the model responds to increasing production by allocating more trains and adding another double car dumper system to the unloading rail terminal is noteworthy. It appears that after solving the loading problem with a higher capacity silo in Brumado, the unloading facility remains the bottleneck of the system. Another important finding is that for all scenarios tested, the duplication in FIOL mainline route and the addition of lines in arrival/departure yards were not chosen as alternatives. First, it seems that besides being a costly intervention, the current trackage configuration in single lines are sufficient to the current volume of traffic. Secondly, adding lines in departure yards is a costly alternative and do not bring any improvement in times as the single benefit is releasing the traffic in the mainline route.

\section{CONCLUSION}

This work presented a hybrid simulation-optimization model to define the best set of supplementary investments in the iron ore corridor of the West-East Integration Railroad (FIOL), in Brazil. A state-of-the-art review was carried out to demonstrate the existing gap in simulation network literature addressing strategic decision-making integrating mainline tracks, loading and unloading operations. A dynamic model of the system was developed in software Arena, including train traffic in single lines and operations in loading and unloading facilities. Dispatching rules were developed to avoid real-world prohibited train movements that result in collisions and deadlocks. After validation, preliminary simulation results demonstrated that the proposed system configuration cannot meet the current iron ore production goals. It was proven that isolated solutions in the bottlenecks of a closed-loop railway network was not effective as the queues are merely transferred within the system. In order to present a cost-effective solution, we minimized a capital cost function comprising investments in the mainline of the railroad, enhancements in terminal areas and fleet sizing. For 3 production levels, the search algorithm of the OptQuest software was able to find the best solutions by improving both silo loading and car dumper systems and increasing the number of trains.

\section{REFERENCES}

Abril, M. et al. (2008) 'An assessment of railway capacity', Transportation Research Part E: Logistics and Transportation Review, 44(5), pp. 774-806. doi: 10.1016/j.tre.2007.04.001.

Assad, A. A. (1980) 'Models for Rail Transportation', Transportation Research Part A: General, 14(3), pp. $205-220$.

Atanassov, I. and Dick, C. T. (2015) 'Capacity of Single-Track Railway Lines with Short Sidings to Support 
Operation of Long Freight Trains', Transportation Research Record: Journal of the Transportation Research Board, 2475(1), pp. 95-101. doi: 10.3141/2475-12.

Bahia (2011) Estudo de Impacto Ambiental (EIA) do Porto Sul - Tomo 1 Caracterização do Empreendimento.

Behiri, W., Belmokhtar-berraf, S. and Chu, C. (2018) 'Urban freight transport using passenger rail network : Scienti fi c issues and quantitative analysis', Transportation Research Part E. Elsevier, 115(May 2018), pp. 227-245. doi: 10.1016/j.tre.2018.05.002.

Brasil (2010) EF-334 - Ferrovia de Integração Oeste Leste (Estudos Operacionais). Available at: http://www.valec.gov.br/acoes_programas/FerroviaIntegracaoOesteLeste.php (Accessed: 20 March 2019).

Brasil (2019) Ferrovia de Integração Oeste Leste (FIOL), VALEC website. Available at: http://valec.gov.br/ferrovias/ferrovia-de-integracao-oeste-leste (Accessed: 20 March 2019).

Caimi, G., Kroon, L. and Liebchen, C. (2017) 'Models for railway timetable optimization: Applicability and applications in practice', Journal of Rail Transport Planning and Management. Elsevier Ltd, 6(4), pp. $285-312$. doi: 10.1016/j.jrtpm.2016.11.002.

Camargo, P. V. De and Barbieri, C. (2012) 'An hybrid simulation-optimization model for assessing the capacity of a closed-loop rail transport system for bulk agricultural grains (written in Portuguese)', Journal of Transport Literature, 6, pp. 33-65.

Corman, F. and Quaglietta, E. (2015) 'Closing the loop in real-time railway control : Framework design and impacts on operations', Transportation Research Part C. Elsevier Ltd, 54, pp. 15-39. doi: 10.1016/j.trc.2015.01.014.

Crainic, T. G. and Laporte, G. (1997) 'Planning models for freight transportation', European Journal of Operational Research, 97(3), pp. 409-438. doi: 10.1016/S0377-2217(96)00298-6.

Crainic, T. G., Perboli, G. and Rosano, M. (2018) 'Simulation of intermodal freight transportation systems : a taxonomy', European Journal of Operational Research. Elsevier B.V., 270(2), pp. 401-418. doi: 10.1016/j.ejor.2017.11.061.

Dessouky, M. M. and Leachman, R. C. (1995) 'A Simulation Modeling Methodology for Analyzing Large Complex Rail Networks', Simulation, 65(August 1995), pp. 131-142. doi: 10.1177/003754979506500205.

Dessouky, M. M., Lu, Q. and Leachman, R. C. (2002) 'Using simulation modeling to asses rail track infrastructure in densely trafficked metropolitan areas', in. doi: 10.1109/WSC.2002.1172953.

Dingler, M. H., Lai, Y.-C. and Barkan, C. . P. L. (2014) 'Effect of Train Type Heterogeneity on Single-Track Heavy Haul Railway Line Capacity', in Proceedings of the Institution of Mechanical Engineers, Part F: Journal of Rail and Rapid Transit, pp. 845-856.

De Faria, C. H. F. and Cruz, M. M. D. C. (2015) 'Simulation modelling of Vitória-Minas closed-loop rail network', Transport Problems, 10, pp. 126-139.

Ferreira, L. (1997) 'Planning Australian Freight Rail Operations: An Overview', Transportation Research part 
A: Policy and practice, 8564(4), pp. 335-348.

Fioroni, M. M. et al. (2005) 'Railroad infrastructure simulator', Proceedings - Winter Simulation Conference, 2005, pp. 2581-2584. doi: 10.1109/WSC.2005.1574554.

Fioroni, M. M. (2008) Closed-loop simulation of rail networks and its applications in Brazil: evaluation of empty car distribution alternatives (written in portuguese). Universidade de São Paulo. Available at: http://www.teses.usp.br/teses/disponiveis/3/3135/tde-03062008-180002/.

Fioroni, M. M. et al. (2013) 'Signal-oriented railroad simulation', Proceedings of the 2013 Winter Simulation Conference - Simulation: Making Decisions in a Complex World, WSC 2013, (1998), pp. 3533-3543. doi: 10.1109/WSC.2013.6721715.

Franzese, L. A. G., Fioroni, M. M. and Botter, R. C. (2003) 'Railroad Simulator on Closed Loop', in Proceedings of the 2003 Winter Simulation Conference, pp. 1602-1606.

Gorman, M. F. (2009) 'Statistical estimation of railroad congestion delay', Transportation Research Part E. Elsevier Ltd, 45(3), pp. 446-456. doi: 10.1016/j.tre.2008.08.004.

Hernando, A., Roanes-Lozano, E. and García-Álvarez, A. (2010) 'An accelerated-time microscopic simulation of a dedicated freight double-track railway line', Mathematical and Computer Modelling. Elsevier Ltd, 51(910), pp. 1160-1169. doi: 10.1016/j.mcm.2009.12.032.

Layeb, S. B. et al. (2018) 'Computers \& Industrial Engineering A simulation-optimization approach for scheduling in stochastic freight transportation', Computers \& Industrial Engineering. Elsevier, 126(October 2017), pp. 99-110. doi: 10.1016/j.cie.2018.09.021.

Marinov, M. et al. (2013) 'Railway operations, time-tabling and control', Research in Transportation Economics, 41(1), pp. 59-75. doi: 10.1016/j.retrec.2012.10.003.

Marinov, M. and Viegas, J. (2011) ‘A mesoscopic simulation modelling methodology for analyzing and evaluating freight train operations in a rail network', Simulation Modelling Practice and Theory. Elsevier B.V., 19(1), pp. 516-539. doi: 10.1016/j.simpat.2010.08.009.

Marinov, M., Zunder, T. and Islam, D. M. Z. (2010) 'Concepts, Models and Methods for Rail Freight and Logistics Performances : an Inception Paper', in Proceedings Media of the 12th World Conference on Transport Research, pp. 1-26.

Medanic, J. and Dorfman, M. J. (2002) 'Efficient scheduling of traffic on a railway line', Journal of Optimization Theory and Applications, 115(3), pp. 587-602. doi: 10.1023/A:1021255214371.

Michal, G. et al. (2017) 'RailNet: A simulation model for operational planning of rail freight', in Transportation Research Procedia. Elsevier B.V., pp. 461-473. doi: 10.1016/j.trpro.2017.05.426.

Motraghi, A. and Marinov, M. V. (2012) 'Analysis of urban freight by rail using event based simulation', Simulation Modelling Practice and Theory. Elsevier B.V., 25, pp. 73-89. doi: 10.1016/j.simpat.2012.02.009.

Oliveira, J. B., Lima, R. S. and Montevechi, J. A. B. (2016) 'Perspectives and relationships in Supply Chain 
Simulation : A systematic literature review', Simulation Modelling Practice and Theory, 62, pp. 166-191. doi: 10.1016/j.simpat.2016.02.001.

Pachl, J. (2007) ‘Avoiding Deadlocks in Synchronous Railway Simulations', in 2nd International Seminar on Railway Operations Modelling and Analysis, pp. 1-10.

Petersen, E. R. and Taylor, A. J. (1982) 'A Structured Model for Rail Line Simulation and Optimization', Transportation Science, 16(2), pp. 192-206. doi: 10.1287/trsc.16.2.192.

Pouryousef, H. and Lautala, P. (2015) 'Hybrid simulation approach for improving railway capacity and train schedules', Journal of Rail Transport Planning \& Management. Elsevier Ltd, 5(4), pp. 211-224. doi: 10.1016/j.jrtpm.2015.10.001.

Sogin, S., Barkan, C. P. L. and Saat, M. R. (2011) 'Simulating the Effects of Higher Speed Passenger Trains in Single Track Freight Networks', in Proceedings of the 2011 Winter Simulation Conference (WSC), pp. 36843692.

Woroniuk, C. and Marinov, M. (2013) 'Simulation modelling to analyse the current level of utilisation of sections along a rail route', Journal of Transport Literature, 7(2), pp. 235-252. doi: 10.1590/s2238-

10312013000200012. 